\title{
Anthropometric and Physical Characteristics of Tunisians Young Soccer Players
}

\author{
Mehdi Ben Brahim ${ }^{1}$, Rym Bougatfa ${ }^{2}$, Amri Mohamed ${ }^{2}$ \\ ${ }^{1}$ Laboratory of Physiology, Faculty of Sciences of Tunis, University of Tunis, Tunis, Tunisia \\ ${ }^{2}$ Laboratory Adaptations Cardio-Circulatory, Respiratory, Metabolic and Hormonal to Muscular Exercise, \\ Faculty of Medicine Ibn El Jazzar, University of Sousse, Sousse, Tunisia \\ Email: mehdi.ben-brahim@hotmail.fr
}

Received April 20 $0^{\text {th }}, 2013$; revised May 20 $0^{\text {th }}, 2013$; accepted May $27^{\text {th }}, 2013$

\begin{abstract}
Copyright (C) 2013 Mehdi Ben Brahim et al. This is an open access article distributed under the Creative Commons Attribution License, which permits unrestricted use, distribution, and reproduction in any medium, provided the original work is properly cited.
\end{abstract}

\begin{abstract}
The aim of this investigation was to provide anthropometric, physical and physiological performance characteristics of Tunisian young soccer players and to examine the relationship between selected parameters according to their playing standard position. One hundred under 13 years old (U-13) male soccer players were tested. They were classified according to their playing standard positions (goalkeeper: GK, defender: DF, midfield: MF, and forward: FW). Testing consisted of anthropometric measurements including weight, height, and body mass index, and performance measures of speed $(5,15$, and $20 \mathrm{~m})$, agility run (Agility-15 m and Ball-15 m), vertical jumping, ball shooting, and aerobic capacity (Hoff Dribble Test and Yo-Yo intermittent Endurance Run, YYIER). GK were taller and heavier than other players. Significant differences of playing positions for the majority of the physical tests include $20 \mathrm{~m}$ sprint, Agility-15 $\mathrm{m}$ and Ball-15 $\mathrm{m}$ times (all $p<.01$ ), as well as squat jump and counter movement jump (all $p<.01$ ). In addition, weight was significantly correlated with $20 \mathrm{~m}$ sprint $(\mathrm{r}=.29, p<.01)$, Agility-15 $\mathrm{m}(\mathrm{r}=.30, p$ $<.01)$ and Ball-15 m $(\mathrm{r}=.31, p<.01)$ times as well as ball shooting speed $(\mathrm{r}=-.42, p<.01)$. Multiple regression analyses showed that weight and height were the most significant predictors of $20 \mathrm{~m}$ sprint time and the YYIER distance, respectively. In conclusion, performance abilities between positions in young soccer players appear to be different. Anthropometry can discriminate physical capacities and soccer skills providing a scientific rational behind the coaches' practice of selecting young soccer players.
\end{abstract}

Keywords: Young Soccer Players; Anthropometric; Performance; Playing Positions; Relationship

\section{Introduction}

Soccer is the most popular worldwide sport which is characterized by high intensity, short-term actions and pauses of varying length (Stroyer, Hansen, \& Klausen, 2004). To succeed in a team sport, soccer players need the optimal combination of technical, tactical, physical characteristics (like somatotype) and mental motivation (Bangsbo \& Michalsik, 2002). Indeed, many experts in the field, such as soccer coaches, managers and scientists believe that the success of this sport can be associated with anthropometric characteristics of players. Also, some previous studies have focused on the relationship between anthropometric profiles of players and their standard positions (Rienzi, Drust, Reilly, Carter, \& Martin, 2000; Gil, Ruiz, Irazusta, \& Irazusta, 2007). Goalkeepers are taller than central position players (Reilly, Bangsbo, \& Franks, 2000), such as defensive and offensive central players (Reilly, Williams, Nevill, \& Franks, 2000). Similar studies on position-specific anthropometric profiles have been reported for Australian football (Young, Newton, Doyle, Chapman, Cormack, Stewart et al., 2005; Pyne, Duthie, Saunders, Petersen, \& Portus, 2006), Gaelic football (Mcintyre \& Hall, 2005; Mcintyre, 2005), rugby (Duthie, Pyne, \& Hooper, 2003) and American football (Mcgee \& Burkett, 2003). So, we can hypothesize positional difference existing in anthro- pometry as soccer coaches would have believed that this shortterm benefits and purposively selects some players with a body type for specific positions. It is evident from the foregoing that most research has focused either on amateur players or professional players on the senior which pushed us to work with young footballers aged under 13, pre-pubescent age. Information in this regard may be helpful to trainers and strength conditioning coaches for enhancing players' specific performance and talent selection. The aim of the present study was to describe anthropometric, physical and physiological performance characteristics of Tunisian football players under 13 years old and to examine the relationship between selected parameters according to their playing standard position.

\section{Methods}

\section{Subjects}

One hundredyoung male soccer players (age under 13 years) from six different teams belonging in first division of the Tunisian Championship participated in this study, which was conducted during the competitive season. They performed soccer training five times a week and played in one competitive match during the weekends. The participants were from a range of outfield playing positions. Following completion of a screening 
questionnaire, written informed consent and parental consent was obtained from all participants in accordance with the international ethical standards. The data collection took place during May (towards the end of the Tunisian season), so teams were well-established.

\section{Anthropometric Measures}

Participants reported to the laboratory for the measurement of height, body mass and percentage body fat. Body mass was measured to the nearest $.1 \mathrm{~kg}$ using an electronic scale (Seca Instruments Ltd., Hamburg, Germany) and height was measured to the nearest $.001 \mathrm{~m}$ using a stadiometer (Holtain Ltd., Crymych, UK). Skinfold thickness at four sites (biceps, triceps, subscapular, and suprailiac) was measured using Harpenden callipers (Lange, Cambridge, MA, USA). All the data were collected by the authors who were experienced in taking skin fold thicknesses.

\section{Performance Measures}

Before the start of trials, a standard warm-up was achieved including some exercise of jogging, dynamic stretching and a series of sprints. Knowing that all subjects are used to this kind of exercise so familiar with the protocols of the various tests of this study, each player was verbally encouraged to give as his maximum effort during the tests. To ovoid the chronobiology bias on physical performances, all tests have been performed during the period of May under conditions of temperature $\left(15^{\circ} \mathrm{C}\right.$ to $\left.22^{\circ} \mathrm{C}\right)$ in the same moment of day $(8 \mathrm{~h} \mathrm{am})$ and after being informed about the nutritional status of subjects (balanced morning meal).

\section{Sprint Tests: (5, 10 and $30 \mathrm{~m})$}

The participants performed three maximal 30-m sprints (with 5- and 10-m split times) on an indoor synthetic court. During recovery $(2-3 \mathrm{~min})$, the participants walked back to the starting line and then waited for the next sprint. Time was recorded using photo-cell gates (Brower Timing Systems, Salt Lake City, UT, USA, accuracy of $.01 \mathrm{~s}$ ) placed $.4 \mathrm{~m}$ above the ground. The participants started the sprint when they feel ready from a standing start $.5 \mathrm{~m}$ behind the first timing gate. Stance for the start was consistent for all participants. The best performance of both trials of 30-m time was selected for analysis.

\section{Squat Jump}

The subject started from a semi-squat position with the hands held at the hips to avoid upper limb body contribution and jumped upward as high as possible. This test was used to estimate muscle power under concentric condition. A successful trial was one where there was no sinking or countermovement before the execution of the jump. The intra-class correlation coefficient (ICC) of the squat jump (SJ) in our study was .96 (95\% confidence interval $[\mathrm{CI}]: .91-.98)$ with no significant differences between the 2 trial scores $(p=.62$, effect size [ES] $=.05$ [trivial]).

\section{Counter Movement Jump}

The subject began from an upright standing position, per- formed a very fast preliminary downward eccentric action followed immediately by a jump for maximal height. Hands remained at the hips for the entire movement to eliminate any influence of arm swing. The ICC of the countermovement jump (CMJ) in our study was .97 (95\% CI: .92 - .99) with no significant differences between the 2 trial scores $(p=.91$, ES $=.01$ [trivial]).

\section{5-m Agility Runs (Agility-15 m)}

In this test, players' velocity in a $15-\mathrm{m}$ agility run was measured using the same photocell gates system as above. As proposed by Mujika et al. (2009), players started running $3 \mathrm{~m}$ behind the initial set of gates. After $3 \mathrm{~m}$ of line running, players entered a $3-\mathrm{m}$ slalom section marked by three sticks $1.6 \mathrm{~m}$ of height and placed $1.5 \mathrm{~m}$ apart, and then cleared a $.5 \mathrm{~m}$-height hurdle placed $2 \mathrm{~m}$ beyond the third stick. Players finally ran 7 $\mathrm{m}$ to break the second set of photocell gates, which stopped the timer. Each player performed two maximal Agility $15 \mathrm{~m}$ interspersed with $3 \mathrm{~min}$ of passive recovery, and the fastest time achieved was recorded.

\section{5-m Ball Dribbling (Ball-15 m)}

Five minutes after the Agility-15 m, players performed the Ball-15 m (Mujika, Santisteban, Impellizzeri, \& Castagna, 2009). This test was similar to the Agility- $15 \mathrm{~m}$, but players were required to dribble a ball while performing the test. After the slalom section of the test, the ball was kicked under the hurdle while the player cleared it. The player then kicked the ball towards either of two small goals placed diagonally $7 \mathrm{~m}$ on the left and the right sides of the hurdle, and sprinted to the finish line. Each player performed two maximal Ball $15 \mathrm{~m}$ interspersed with $3 \mathrm{~min}$ of passive recovery, and the fastest time achieved was recorded.

\section{Ball Shooting Test}

The players performed maximal velocity instep place kicks of a stationary ball. A ball of FIFA standard size and inflation was kicked $4 \mathrm{~m}$ toward a target $131 \mathrm{~m}$ in size (Dorge, Anderson, Sorensen, \& Simonsen, 2002). Players were asked to strike the ball as hard as possible and 5 shots were allowed for each player with 1-minute rest between shots (Cometti, Maffiuletti, Pousson, Chatard, \& Maffulli, 2001). Ball speed was measured by a radar gun (Sports Radar Gun SRA 3000; Precision Training Instrument, IL) located $.3 \mathrm{~m}$ to the stationary ball and pointed toward the target according to the instruction manual. The shot that hit the target and produced the highest ball speed was selected for analysis.

\section{Hoff Dribble Test}

The Hoff dribble test which proposed by Hoff et al. (2002) is a soccer-specific dribbling track in which players have to dribble the ball through routed obstacles. Before the test, players were instructed to jog slowly through the route for 1 lap to familiarize themselves, followed by a self-pace dribble for another lap. The distance for 1 lap has been established at $290 \mathrm{~m}$ such as proposed by Chamari et al. (2005). As previously described the purpose of this test was to cover the maximum distance during a 10 minute period. 


\section{Yo-Yo Intermittent Endurance Run}

Because soccer includes high-intensity intermittent bouts of exercise, which stresses the anaerobic glycolysis metabolic pathway (Drust, Cable, \& Reilly, 2000), YYIER (level 1) is close to the soccer exercise pattern. In this test, the players had to perform a series of $20 \mathrm{~m}$ shuttle runs at a pace set by an audio metronome with a standard rest interval between shuttles (5 seconds) (Bangsbo \& Michalsik, 2002). The time allowed for the shuttles was progressively decreased, that is, the speed was increased. The test was terminated when the player was unable to maintain the required speed. The distance covered in the shuttles was recorded for analysis, but the distance covered during rest intervals was excluded (Castagna, Impellizzeri, Belardinelli, Abt, Coutts, Chamari et al., 2006).

Tests were performed over three days with 5 min of recovery in-between in the following order: 1 day, maximal 30-m sprints, $\mathrm{SJ}, \mathrm{CMJ}$ and $15 \mathrm{~m}$ agility test with and without ball; $2^{\text {nd }}$ day, ball shooting and Hoff dribble test; and 3rd day, YYIER.

\section{Statistical Analysis}

The statistical study is based on a sample of 100 players. Different oven positions were determined: the goalkeepers (GK), the defenders (DF), the midfielders (MF) and the forwards (FW). Statistical analysis was performed using SPSS version 18.0 (SPSS Inc., Chicago, HIM (IT), and the USA). Pearson product-moment correlations were used to examines the relationship between anthropometric, physiological, and performance variables. The method of linear regression was used for determining the impact of the anthropometric characteristics on the physical and physiological performances. This relation can be represented analytically as follows: (physiological perform- ances) $=\mathrm{f}$ (height or weight). The linear relation between the anthropometric characteristics and the physical and physiological performances is represented by several regressions (R1, R2, R3, R4, R5, R6, R7, and R8). A one-way analysis of variance (ANOVA) and Post Hoc Test was used to determine if significant differences existed between the player's positions. Pair wise comparisons were made using Bonferroni adjustment to control the type one error rate. Level of significance was defined as $p \leq .05$.

\section{Results}

The subjects' age, anthropometric and physical performance data are summarized in Table 1, and significant differences between groups are indicated. GK were heavier and taller than DF, MF and FW $(p<.01)$. In the same way, significant difference of positions for the majority of the physical tests including 20 $\mathrm{m}$ sprint time, Agility-15 $\mathrm{m}$ and Ball-15 m, SJ, CMJ, YYIER distance and ball shooting speed (all $p<.01$ ). Significant positional difference was also found in Hoff dribbling distance, since MF performed $64.5 \mathrm{~m}$ greater than the DF.

Body weight was significantly correlated with 20 msprint time $(\mathrm{r}=.29, p<.01)$, Agility-15 $\mathrm{m}$ and Ball- $15 \mathrm{~m}$, ball shooting speed $(\mathrm{r}=-.42, p<.01)$, Hoff dribbling and the YYIER tests $(p<.01)$, as well as with SJ and CMJ $(p<.05)$. The body mass is so significantly correlated to most of the physical and physiological characteristics studied $(p<.01)$. The body mass index is not significantly correlated with all performances (Table 2 ).

Multiple regressions between anthropometry and testing physical performances are summarized in Table 3 . We notice that the effect of the height and the body mass are globally significant on the totality of the physical and physiological perfor-

Table 1.

Anthropometric and physiological performances of playing position standards.

\begin{tabular}{|c|c|c|c|c|c|}
\hline & GK & $\mathrm{DF}$ & MF & FW & $P$-value \\
\hline $\mathrm{n}$ & 14 & 26 & 34 & 26 & \\
\hline Age (y) & $12.4( \pm .51)$ & $12.3( \pm .48)$ & $12.4( \pm .50)$ & $12.4( \pm .50)$ & NS \\
\hline Soccer experience $(y)$ & $3.0( \pm 1.03)$ & $2.9( \pm 1.09)$ & $2.9( \pm 1.07)$ & $3.0( \pm .84)$ & NS \\
\hline Height (cm) & $159( \pm 6.56)$ & $153( \pm 6.80)$ & $149( \pm 5.64)$ & $150( \pm 7.39)$ & $.000^{* *}$ \\
\hline Body mass (kg) & $48.8( \pm 5.15)$ & $45.8( \pm 4.86)$ & $42.3( \pm 4.17)$ & $44.5( \pm 6.83)$ & $.002^{* *}$ \\
\hline BMI $\left(\mathrm{kg} \cdot \mathrm{m}^{-2}\right)$ & $19.1( \pm 2.05)$ & $19.3( \pm 1.41)$ & $19.0( \pm 2.15)$ & $19.6( \pm 2.74)$ & NS \\
\hline $5 \mathrm{~m}$ sprint (s) & $1.20( \pm .04)$ & $1.17( \pm .06)$ & $1.17( \pm .07)$ & $1.19( \pm .07)$ & NS \\
\hline $20 \mathrm{~m}$ sprint (s) & $3.88( \pm .07)$ & $3.37( \pm .05)$ & $3.30( \pm .07)$ & $3.52( \pm .09)$ & $.000^{* *}$ \\
\hline Agility-15 m (s) & $5.01( \pm .23)$ & $4.32( \pm .19)$ & $4.24( \pm .15)$ & $4.56( \pm .13)$ & $.000^{* *}$ \\
\hline Ball-15 m (s) & $5.77( \pm .22)$ & $5.36( \pm .18)$ & $4.98( \pm .17)$ & $5.12( \pm .20)$ & $.000^{* *}$ \\
\hline $\mathrm{SJ}(\mathrm{cm})$ & $29.30( \pm 2.87)$ & $27.39( \pm 4.25)$ & $25.49( \pm 2.95)$ & $26.86( \pm 3.44)$ & $.007^{* *}$ \\
\hline $\mathrm{CMJ}(\mathrm{cm})$ & $32.55( \pm 3.21)$ & $29.41( \pm 4.29)$ & $27.41( \pm 3.92)$ & $28.29( \pm 3.81)$ & $.001^{* *}$ \\
\hline Ball shooting $\left(\mathrm{km} \cdot \mathrm{h}^{-1}\right)$ & $68.32( \pm 5.93)$ & $7.12( \pm 8.56)$ & $69.46( \pm 7.93)$ & $71.28( \pm 5.45)$ & $.000^{* *}$ \\
\hline Hoff dribbling test $(\mathrm{m})$ & $980( \pm 111)$ & $1167( \pm 94)$ & $1231( \pm 105)$ & $1202( \pm 126)$ & $.000^{* *}$ \\
\hline YYIER (m) & $1400( \pm 89)$ & $1580( \pm 283)$ & $2018( \pm 203)$ & $1680( \pm 271)$ & $.000^{* *}$ \\
\hline
\end{tabular}

Note: ${ }^{* *} p<.01$. Data are mean $\pm \mathrm{SD}$. GK = goalkeeper; $\mathrm{DF}=$ defender; $\mathrm{MF}=$ midfielder; $\mathrm{FW}=$ forward; $\mathrm{n}=$ sample size; BMI = body mass index; YYIER = Yo-Yo intermittent endurance run, $\mathrm{NS}=$ no significant difference. 
Table 2.

Correlation between anthropometric and physical performances $(\mathrm{n}=100)$.

\begin{tabular}{|c|c|c|c|}
\hline Anthropometrics & Physiological performances & $\mathrm{r}$ & $r^{2}$ \\
\hline \multirow{8}{*}{ Height } & $20 \mathrm{~m}$ sprint time & $.29^{* *}$ & $.08^{* *}$ \\
\hline & Agility- $15 \mathrm{~m}$ time & $.36^{* *}$ & $.12^{* *}$ \\
\hline & Ball-15 m time & $.41^{* *}$ & $.16^{* *}$ \\
\hline & SJ height & $.2^{*}$ & $.04^{*}$ \\
\hline & CMJ height & $.19^{*}$ & $.03^{*}$ \\
\hline & Ball shooting speed & $-.42^{* *}$ & $.17^{* *}$ \\
\hline & Hoff dribble distance & $-.43^{* *}$ & $.18^{* *}$ \\
\hline & YYIER distance & $-.24^{*}$ & $.05^{*}$ \\
\hline \multirow{7}{*}{ Body mass } & $20 \mathrm{~m}$ sprint time & $.34^{* *}$ & $.11^{* *}$ \\
\hline & Agility-15 m time & $.30^{* *}$ & $.09^{* *}$ \\
\hline & Ball-15 m time & $.31^{* *}$ & $.09^{* *}$ \\
\hline & SJ height & $.23^{*}$ & $.05^{*}$ \\
\hline & CMJ height & $.25^{* *}$ & $.06^{* *}$ \\
\hline & Hoff dribble distance & $-.35^{* *}$ & $.12^{* *}$ \\
\hline & YYIER distance & $-.40^{* *}$ & $.16^{* *}$ \\
\hline
\end{tabular}

Note: ${ }^{*} p<.05 ;{ }^{* *} p<.01 ; \mathrm{BMI}=$ body mass index; YYIER $=$ Yo-Yo intermittent endurance run.

Table 3.

Multiple regression analyses with body mass and body height as independent variable.

\begin{tabular}{|c|c|c|c|c|c|c|c|c|}
\hline & $20 \mathrm{~m}$ sprint & Agility-15 m & Ball-15 m & SJ & CMJ & YYIER & Hoff test & Ball shooting \\
\hline Regression & R1 & R2 & R3 & R4 & R5 & R6 & R7 & R8 \\
\hline Constant & $\begin{array}{l}2.29 \\
(5.04)^{* * *}\end{array}$ & $\begin{array}{l}2.52 \\
(4.56)^{* * *}\end{array}$ & $\begin{array}{l}2.94 \\
(5.46)^{* * *}\end{array}$ & $\begin{array}{l}13.68 \\
(1.8)^{*}\end{array}$ & $\begin{array}{c}14.7 \\
(1.69)^{*}\end{array}$ & $\begin{array}{l}3599 \\
(8.15)^{* * *}\end{array}$ & $\begin{array}{l}2158 \\
(9.40)^{* * *}\end{array}$ & $\begin{array}{c}74.9 \\
(37.22)^{* * *}\end{array}$ \\
\hline Height & $\begin{array}{c}.005 \\
(1.32)\end{array}$ & $\left(_{(2.44)^{* *}}^{.01}\right.$ & ${(3.16)^{* * *}}^{.013}$ & $\begin{array}{l}.055 \\
(.93)\end{array}$ & $\begin{array}{l}.04 \\
(.68)\end{array}$ & $\begin{array}{c}-9.88 \\
(-2.93)^{* * *}\end{array}$ & $\begin{array}{c}-4.97 \\
(-2.81)^{* * *}\end{array}$ & $\begin{array}{c}-.03 \\
(-2.24)^{* *}\end{array}$ \\
\hline Body mass & $(2.25)^{* *}$ & $\begin{array}{c}.008 \\
(1.38)\end{array}$ & $\begin{array}{l}.006 \\
(1.11)\end{array}$ & $\begin{array}{l}.0109 \\
(1.43)\end{array}$ & $\begin{array}{c}.16 \\
(1.82)^{*}\end{array}$ & $\begin{array}{l}-7.23 \\
(-1.65)\end{array}$ & $\begin{array}{c}-5.09 \\
(-2.21)^{* *}\end{array}$ & $\begin{array}{l}.007 \\
(.33)\end{array}$ \\
\hline $\mathrm{R}^{2}$ & $13.1 \%$ & $14.7 \%$ & $18.4 \%$ & $06 \%$ & $07 \%$ & $19 \%$ & $22.6 \%$ & $06 \%$ \\
\hline $\mathrm{F}$ & $.001^{* * *}$ & $.000^{* * *}$ & $.000^{* * *}$ & $.04^{* *}$ & $.02^{* *}$ & $.000^{* * *}$ & $.000^{* * *}$ & $.04^{* *}$ \\
\hline
\end{tabular}

Note: ${ }^{*} p<.05 ;{ }^{* *} p<.01 ;{ }^{* * *} p<.001,($ ): t student, F: statistic fisher.

mances except the test of speed $5 \mathrm{~m}$ (results not represented in Table 3).

The value of the probability relative to the statistics of Fisher for $\mathrm{R} 1$ is of the order of $.001<.05$ what shows us that the height and the weight of the players of the category U13 have an importing effect on the test of speed 20 meters. R3 showed that height and body mass affect globally the test of agility without ball with an explanation of the order of $14.7 \%$ but only the variable of weight is statistically significant and exercises a positive impact on the agility test without ball $\left(\mathrm{t}_{\text {student }}=2.44>\right.$ 1.96). $\mathrm{R} 7$ is the best model so showing the effect of the height and the weight on Hoff test, in particular the weight is statistically significant $(p<.05)$, and the weight also is statistically significant $(p<.01)$. These two parameters act negatively on the performance of this test and explain approximately $22.6 \%$ of the variation of this test for the young football players (U13).

\section{Discussion}

\section{Positional Differences in Anthropometry}

The results of the present study showed significant differences between playing position standards concerning the anthropometric measures, especially body weight and height. In agreement with Gill et al. (2007), GKs were heavier and taller than other playing position groups. Similar characteristics would help GKs in aerial duels allowing them to defend their goals. Other anthropometric differences according to playing position were identified. Our results are consistent in partly with the findings of Malina et al. (2000) who found, in soccer players aged 11 to 16 years old, that FWs were taller than DFs and GKs were heavier than MFs, whereas FWs were shorter than MFs, GKs, and DFs. In the contrary, no playing position effect was noted between four positions concerning BMI. Our data are si- 
milar to those reported by Slavko et al. (2011) in amateur German football players but different to those reported by Wong et al. (2009) in Under 14 years soccer players. This discrepancy could be explained in part by the sample size, the different methods of measurement as well as the performance level. The results of the current study showed substantial variations in stature and body mass suggesting that there are different physical demands in each playing position standard. Accordingly, Reilly et al. (2000) have concluded that elite soccer teams are characterized by relative heterogeneity in body size. Therefore, there are likely to be anthropometric predispositions for positional roles, with taller players being the most suitable for central defensive positions and for the "target" player among the strikers or forwards. This factor may be linked with pres election of early maturers for key positional roles, where body size rather than playing skills provides an advantage.

\section{Positional Differences in Physical and Physiological Performances}

The data of physical and physiological performances are different according to playing position standards. In fact, a significant difference is shown for the $20 \mathrm{~m}$ sprint time with the best performance observed in MFs. The results of present study are in agreement with Gil et al. (2007) who showed that FDs were faster than DFs and MFs at the $30 \mathrm{~m}$ sprint test and disagree with the study of Malina et al. (2005). Accordingly, Di Salvo et al. (2007) highlighted that FW covered the greater distance at very high-intensity run compared with DF and MF. In summary, the U13 soccer players have a level of sprint and performance significantly different among playing positions, but when it is approaching the professional level, positional differences exist, where FWs become the fastest sprinters as they cover the greatest distance by high speed during games. Consistent with Wong et al. (2009), no difference between playing positions was found in $5 \mathrm{~m}$ and $10 \mathrm{~m}$ sprint times. In addition, a significant difference of position is shown concerning Hoff dribbling test where MF covered the best distance in the group (MF: 1231, GK: $980 \mathrm{~m}$ ) which is in agreement with the results of Di Salvo et al. (2008). Similar results were found in seniors professional football players (Di Salvo, Baron, Tschan, Calderon Montero, Bachl, \& Pigozzi, 2007).

In contrast with results of previous studies (Wong, Mujika, Castagna, Chamari, Lau, \& Wisloff, 2008) performed on Under 13 to Under 15 players, our results showed that there is significant difference in jump height (SJ and CMJ) between the GK, $\mathrm{DF}, \mathrm{MF}$ and FW. In the present study, GK had the highest jump height and MF had the lowest compare with DF and FW. These results contradict the hypothesis that there is no positional difference in the test of jump for the young football players who having an experience of soccer practice less than five years (Malina, Eisenmann, Cumming, Ribeiro, \& Aroso, 2004). The ball shooting is an important factor in football performance especially in goal concretization. Indeed, a significant difference is observed between the various playing positions which disagree with the results advanced by Wong et al. (2008) and Malina et al. (2005).

A soccer player who is agile is able to change direction abruptly without losing balance. Agility includes factors such as speed, strength, balance and coordination and is beneficial because it helps a player's ability to get and hold onto the ball (Sheppard \& Young, 2006). In our study, we found that there is a significant difference between the various positions of the young players. Indeed, MF present the best performance in this test with or without ball, on the other hand the GK had the bad performance during both tests. The DF is faster than the FW in the test without ball. The opposite is observed in the test with ball.

These results confirm the fact that MF and FW are technically more developed than the DF and the GK in football. In addition, agility training is an important part of any soccer player's regimen because it replicates the various motions players will experience during the run of play. Soccer is a game full of direction and speed changes with and without the ball, and agility training helps players become more agile and improves coordination. Malina et al. (2005) and Wong et al. (2009) confirmed that there is no positional difference in YYIER among $\mathrm{U} 13$ to U15, which is contradictory to the data of the present study.

\section{Relationship between Anthropometric and Physical, Physiological Performances}

Body mass is the most significant predictor of $20 \mathrm{~m}$ sprint time. Indeed, a negative parallelism found in our study between body weight and sprint time is in agreement with the results of Malina et al. (2004) who found that body mass is the most significant predictor of $30 \mathrm{~m}$ sprint time. In addition, our results show that body mass is the most significant predictor of CMJ. On the other hand, consistent with the previous study (Malina, Eisenmann, Cumming, Ribeiro, \& Aroso, 2004), we found that body height is the predictor of vertical jump performance. In contrast to Wong et al. (2002), we found a negative relationship between the YYIER and body height. Our results suggest that height is not the most predictor of endurance capacity in young soccer players. Other factors such as body weight could be the major determinant of the YYIER. In fact, in our study we found a strong negative relationship between YYIER distance and body weight.

In summary, a high height can be explain by an important muscular mass and a thin body mass index which lead us to say that the football player who enjoys a high height is better in the activities of strength and power than in the activities of endurance. Finally, this research supports but in the short term, the fact that soccer coaches can select young players based on their anthropometry characteristics other than technical and tactical performance (Helsen, Van Winckel, \& Williams, 2005). Therefore, as suggested by Reilly et al. (2000), Rienzi et al. (2000), other factors other than absolute anthropometry advantage, such as psychological and soccer-specific skills should be also considered in the selection of young soccer players for developing future high-class players.

\section{REFERENCES}

Bangsbo, J., \& Michalsik, L. (2002). Assessment and physiological capacity of elite soccer players. In T. Reilly, \& A. Murphy (Eds.), Science and football IV (pp. 53-62). Cambridge, UK: Routledge,

Castagna, C., Impellizzeri, F. M., Belardinelli, R., Abt, G., Coutts, A., Chamari, K., \& D’Ottavio, S. (2006). Cardio respiratory responses to YoYo intermittent endurance test in nonelite youth soccer players. Journal of Strength and Conditioning Research, 20, 326-33.

Chamari, K., Hachana, Y., Kaouech, F., Jeddi, R., Moussa-Chamari, I., \& Wisloff (2005). Endurance training and testing with the ball in young elite soccer players. British Journal of Sports Medicine, 39, 
24-28. doi:10.1136/bjsm.2003.009985

Cometti, G., Maffiuletti, N. A., Pousson, M., Chatard, J. C., \& Maffulli, N. (2001). Isokinetic strength and anaerobic power of elite, subelite and amateur French soccer players. International Journal of Sports Medicine, 22, 45-51. doi:10.1055/s-2001-11331

Di Salvo, V., Baron, R., Tschan, H., Calderon Montero, F. J., Bachl, N., \& Pigozzi, F. (2007). Performance characteristics according to playing position in elite soccer. International Journal of Sports Medicine, 28, 222-227. doi:10.1055/s-2006-924294

Di Salvo, V., Benito, P. J., Calderon, F. J., Di Salvo, M., \& Pigozz, F. (2008). Activity profile of elite goalkeepers during football matchplay. Journal of Sports Medicine and Physical Fitness, 48, 443-446.

Dorge, H. C., Anderson, T. B., Sorensen, H., \& Simonsen, E. B. (2002). Biomechanical differences in soccer kicking with the preferred and the non-preferred leg. Journal of Sports Science, 20, 293-299. doi:10.1080/026404102753576062

Drust, B., Cable, N. T., \& Reilly, T. (2000). Investigation of the effects of the pre-cooling on the physiological responses to soccer-specific intermittent exercise. European Journal of Applied Physiology, 81, 11-17. doi:10.1007/PL00013782

Duthie, G., Pyne, D., \& Hooper, S. (2003). Applied physiology and game analysis of rugby. Union Sports Medicine, 33, 973-991. doi:10.2165/00007256-200333130-00003

Gil, S. M., Gil, J., Ruiz, F., Irazusta, A., \& Irazusta, J. (2007). Physiological and anthropometric characteristics of young soccer players according to their playing position: relevance for the selection process. Journal of Strength and Conditioning Research, 21, 438-445.

Helsen, W. F., Van Winckel, J., \& Williams, A. M. (2005). The relative age effect in youth soccer across Europe. Journal of Sports Science, 23, 629-636. doi: $10.1080 / 02640410400021310$

Hoff, J., Wisloff, U., Engen, L. C., Kemi, O. J., \& Helgerud, J. (2002). Soccer specific aerobic endurance training. British Journal of Sports Medicine, 36, 218-221. doi:10.1136/bjsm.36.3.218

Malina, R. M., Cumming, S. P., Kontos, A. P., Eisenmann, J. C., Ribeiro, B., \& Aroso, J. (2005). Maturity-associated variation in sport-specific skills of youth soccer players aged 13-15 years. Journal of Sports Science, 23, 515-522. doi:10.1080/02640410410001729928

Malina, R. M., Eisenmann, J. C., Cumming, S. P., Ribeiro, B., \& Aroso, J. (2004). Maturity-associated variation in the growth and functional capacities of youth football (soccer) players 13-15 years. European Journal of Applied Physiology, 91, 555-562. doi:10.1007/s00421-003-0995-z

Malina, R. M., Pena Reyes, M. E., Eisenmann, J. C., Horta, L., Rodrigues, J., \& Miller, R. (2000). Height, mass and skeletal maturity of elite Portuguese soccer players aged 11-16 years. Journal of Sports Science, 18, 685-693. doi:10.1080/02640410050120069

Mcgee, K. J., \& Burkett, L. N. (2003). The national football league combine: A reliable predictor of draft status. Journal of Strength and
Conditioning Research, 17, 6-11.

Mcintyre, M. C., \& Hall, M. (2005). Physiological profile in relation to playing position of elite college Gaelic footballers. British Journal of Sports Medicine, 39, 264-266. doi:10.1136/bjsm.2003.011254

Mcintyre, M. C. (2005). A comparison of the physiological profiles of elite Gaelic footballers, hurlers, and soccer players. British Journal of Sports Medicine, 39, 437-439. doi:10.1136/bjsm.2004.013631

Mujika, I., Santisteban, J., Impellizzeri, F. M., \& Castagna, C. (2009). Fitness determinants of success in men's and women's football. Journal of Sports Science, 27, 107-114. doi:10.1080/02640410802428071

Pyne, D. B., Duthie, G. M., Saunders, P. U., Petersen, C. A., \& Portus, M. R. (2006). Anthropometric and strength correlates of fast bowling speed in junior and senior cricketers. Journal of Strength and Conditioning Research, 20, 620-626.

Reilly, T., Bangsbo, J., \& Franks, A. (2000). Anthropometric and physiological predispositions for elite soccer. Journal of Sports Sciences, 18, 669-683. doi:10.1080/02640410050120050

Reilly, T., Williams, A. M., Nevill, A., \& Franks, A. (2000). A multidisciplinary approach to talent identification in soccer. Journal of Sports Sciences, 18, 695-702. doi:10.1080/02640410050120078

Rienzi, E., Drust, B., Reilly, T., Carter, J. E., \& Martin, A. (2000). Investigation of anthropometric and work-rate profiles of elite South American international soccer players. Journal of Sports Medicine and Physical Fitness, 40, 162-169.

Sheppard, J. M., \& Young, W. B. (2006). Agility literature review: Classifications, training and testing. Journal of Sports Science, 24, 919932. doi: $10.1080 / 02640410500457109$

Slavko, R., Hilfiker, R., Claiys, P., Clijsen, R., \& Taeytnansa, J. (2011). Position-specific and Team-ranking-related Morphological characteristics in German Amateur Soccer Players-A Descriptive StudyAnthropometry in Amateur Soccer players. International Journal of Applied Sports Sciences, 23, 8-182.

Stroyer, J., Hansen, L., \& Klausen, K. (2004). Physiological profile and activity pattern of young soccer players during match play. Medicine Sciences Sports Exercises, 36, 168-174. doi:10.1249/01.MSS.0000106187.05259.96

Wong, P., Chamari, K., Dellal, A., \& Wisloff, U. (2009). Relationship between anthropometric and physiological characteristics in youth soccer. Journal of Strength and Conditioning Research, 23, 12041210. doi:10.1519/JSC.0b013e31819f1e52

Wong, P., Mujika, I., Castagna, C., Chamari, K., Lau, P. W. C., \& Wisloff, U. (2008). Characteristics of World Cup soccer players. Soccer Journal, 57-62.

Young, W. B., Newton, R. U., Doyle, T. L., Chapman, D., Cormack, S., Stewart, G., \& Dawson, B. (2005). Physiological and anthropometric characteristics of starters and non-starters and playing positions in elite Australian Rules football: A case study. Journal of Science and Medicine in Sport, 8, 333-345. doi:10.1016/S1440-2440(05)80044-1 